\title{
The Determinants and Impact of Telecommunications Reforms in Developing Countries
}

\author{
FARID GASMI AND LAURA RECUERO VIRTO
}




\title{
The determinants and impact of telecommunications reforms in developing countries*
}

\author{
Farid Gasmi \\ Toulouse School of Economics (ARQADE \& IDEI) \\ Université Toulouse 1 Capitole \\ and \\ Laura Recuero Virto \\ OECD, Paris
}

\begin{abstract}
This paper has two related objectives. First, it seeks to identify the key determinants of some policies that have been at the heart of the reforms of the telecommunications industry in developing countries, namely, liberalization, privatization, and the (re)structuring of regulation. Second, it attempts to estimate the extent to which these policies have translated into actual deployment of telecommunications infrastructure. This simultaneous investigation is conducted by means of an econometric analysis of a 1985-1999 time-series-cross-sectional database on 86 developing countries. Sectoral as well as institutional and financial factors are found to be important determinants of the actual reforms implemented. We uncover a positive relationship between the decision to introduce competition in the digital cellular segment and the growth of the fixed-line segment, suggesting that these two segments have benefited from each other. We also find that countries facing increasing institutional risk and financial constraints are more likely to introduce competition in the digital cellular segment and to privatize the fixed-line incumbent, these policies being economically attractive to both investors and governments. In turn, these policies are those that enhance the deployment of fixed-line infrastructure. In contrast, competition in the analogue cellular segment and the creation of a separate regulator seem to be relatively less attractive policies as they are found to be less likely to be introduced in countries facing increasing institutional risk and budget constraints. Their impact on fixed network deployment is found to be negative or non significant.
\end{abstract}

JEL codes: C23, L51, L96, L98.

Key words: Telecommunications, reforms, institutional risk, financial constraints, developing countries.

September 2009

\footnotetext{
* An earlier version of this paper was presented at the ASSET meeting, Padua, Italy, November 2007, the ADRES meeting, Toulouse, France, January 2008, the meeting of the Royal Economic Society, University College of London, UK, January 2008, and the ISNIE meeting, Toronto, Canada, June 2008. We thank participants to these events for useful comments. We are indebted to E. Auriol, L.H. Gutierrez, R. McNary, R. Rathindran, S. Wallsten, and L.C. Xu for their help in the construction of the database used in this paper, and to D. Filmer for providing some software. We thank T. Magnac, M. Traoré, the editor of this journal, and two anonymous referees for useful comments. Supplemental material to this paper is available from the authors upon request. All remaining errors are ours only, however.
} 


\section{Introduction}

The telecommunications sector has been at the forefront of the wave of reforms that has profoundly reshaped infrastructure industries worldwide by allowing new market configurations and institutions to emerge. Both developed and developing countries have been concerned with enhancing industry suppliers' performance. Competition in some segments of the industry has been introduced, sometimes with (some level of) privatization of state-owned incumbents, and the legal and regulatory framework has been (re)designed with the purpose of enhancing diversification and quality of service, efficiency, and tariffs. However, policy makers in developing countries faced a far more challenging task than their developed countries counterparts. Poor infrastructures, weak economic conditions, and inefficient institutions inherited from the pre-reforms era are all but some of the significant impediments to the advancement of the reforms they had to overcome. Given the scarcity of resources, the question then is how to efficiently allocate these resources among the many objectives.

Gasmi et al. (2006) have empirically shown that political accountability is an important determinant of regulatory performance and argued that policies aimed at enhancing politically accountable systems should be given due attention in development programs. In this paper, we further investigate the relationship between the reforms of the telecommunications sector that have been implemented in developing countries and the evolution of this sector. We approach this issue by attempting to both evaluate the impact of the sectoral reforms on the deployment of infrastructure and identify the main factors that led to the implementation of some specific reforms.

In addition to insufficient deployment of telecommunications technologies and lack of good institutional governance, developing countries are often characterized by poor macroeconomic conditions. The structuration of the reforms in terms of their number, their design, and their timing, as well as their effective impact on the industry performance, are all subject to these constraints. Hence, market outcomes resulting from the telecommunications reforms are not only conditioned by decisions pertaining to the sector itself, but also by the institutional and macroeconomic environment. Factors such as corruption engrained in the political system and lack of democracy 
substantially weaken the efficiency of institutional rules whereas high debt service and inefficient taxation worsen the financial situation.

While the question of the impact of telecommunications reforms on the deployment of infrastructure in developing countries has been fairly well addressed from an empirical standpoint, the issue of the determinants of these reforms has been mainly examined at a theoretical level. ${ }^{2}$ This paper contributes to filling this void by tackling these two issues within a unified empirical framework. Using data on the telecommunications industry in developing countries, we attempt to simultaneously evaluate the impact of the reforms on network expansion and investigate the role that infrastructure deployment, institutional risk, and access to public funds have played in the decisions to introduce competition, privatize the state-owned incumbent operator, and create a separate regulatory authority. The link between sectoral reforms and infrastructure deployment variables is explored by means of a systematic investigation of two-way causal relationships between these variables.

Our search for a two-way causality between reform and network expansion variables also gives us an indication on whether some of our right-hand-side variables should be considered as endogenous in our regressions. One might expect, indeed, that policies such as the introduction of competition and privatization may be endogenous to infrastructure deployment, particularly in the early stages of the reforms. ${ }^{3}$ Moreover, the creation of a separate regulatory entity may also depend on pre-regulatory conditions.

In this paper, we depart from the approach typically followed in the literature to analyze the telecommunications reforms in developing countries by treating separately the analogue and digital segments of the cellular market as far as the the introduction of competition and its impact on fixed network deployment are concerned. Such a separate treatment is warranted by the observation that digital is based on a higher capacity and more efficient technology that allows for a wider range of service offerings. ${ }^{4}$ Moreover, because

\footnotetext{
${ }^{2}$ Fink et al. (2002) provide a comprehensive overview of the empirical stream of the literature. Theoretical contributions include Auriol and Picard (2004), Emerson (2006), Evans et al. (2005), Laffont (2005), and Warlters (2004).

${ }^{3}$ Note that licenses are often granted conditional on the fulfillment of service penetration and quality targets and associated with exclusivity periods.

${ }^{4}$ Digital technology allows to connect up to four times more users than analogue with
} 
analogue and digital licenses are delivered under specific contractual terms and were granted at different points in history, their impact on the development of the telecommunications industry cannot be expected to be the same. ${ }^{5}$ In fact, disentangling the contribution of each of these two segments to the considerable network expansion experienced by developing countries in recent years is one of the main objectives of this study. ${ }^{6}$

The plan of the paper is as follows. The next section summarizes some of the main results recently put forward in the empirical literature on the determinants of the telecommunications reforms and their impact on infrastructure deployment as measured by fixed-line service penetration. Section 3 describes the data set used in this paper consisting of information on the telecommunications industry in 86 developing countries during the period 1985-1999. Section 4 presents our empirical investigation of the determinants of the telecommunications reforms and their impact on infrastructure deployment. Section 5 summarizes our findings, discusses some policy implications, and points to some directions for further research. The appendix contains some tables that present the estimation results. A detailed description of the data used, their sources, and some complementary material are included in a supplemental document available from the authors upon request.

\section{Related literature}

Thanks to the availability of telecommunications data accumulated over the last two decades, a large empirical literature has analyzed the impact of major reforms on infrastructure deployment in this sector. In contrast, the empirical literature exploring the determinants of these reforms is at its infancy and

the same bandwidth. Moreover, the data transmission capabilities of digital allow the offering of SMS and some other more advanced services.

${ }^{5}$ Authorities typically grant operators specific licenses that give them the right to offer exclusively analogue or digital cellular services. Because of superior technological capabilities, digital has attracted much more operators than analogue. A commonly observed industry configuration is two to five operators with digital technology and one with analogue. Analogue licenses being introduced prior to digital, they were typically granted to the fixed service incumbent. Clearly then, one should expect the introduction of digital and analogue cellular services to have a different effect on the development of the fixed network.

${ }^{6}$ Competition between these two segments is however not the focus of this paper. 
mostly deals with political factors. We briefly review some representative studies in each of these two streams of the literature and point to some aspects this paper contributes to.

Most of the studies done so far on the impact of sectoral reforms on infrastructure deployment in developing countries acknowledge that, overall, there exists a robust relationship between variables representing the reforms and variables measuring telecommunications network expansion such as fixed-line service penetration. In particular, the bulk of this literature has come to the conclusion that the introduction of competition has resulted in measurable network deployment and labor efficiency in the fixed-line segment.

Fink et al. (2002) provide an analysis of the impact of competition on fixed-line deployment and labor efficiency in data on 86 developing countries across African, Asian, Middle Eastern, Latin American, and Caribbean countries for the period 1985-1999. Wallsten (2001), Gutierrez (2003), and Ros (2003) use data on a set of African and Latin American countries while Ros (1999) uses data on countries with GDP per capita of less than USD 10,000 and McNary (2001) and $\mathrm{Li}$ and $\mathrm{Xu}$ (2004) use worldwide data. Though McNary (2001), Fink et al. (2002), and Li and Xu (2004) consider the introduction of competition in the fixed-line and cellular segments, to the best of our knowledge, the analogue and digital segments have yet to be addressed separately. This paper is an attempt to do so.

There is not such a consensus on the impact of the privatization of the fixed-line incumbent on network expansion. Some empirical results indicate that this policy has a positive impact on fixed-line deployment. After controlling for tariff re-balancing, Banerjee and Ros (2000) find that privatization reduces unmet demand by approximately $28 \%$ in a data set on 23 Latin American countries for the period 1986-1995. Gutierrez (2003) reports a reduction of unmet demand of the order of 10 to $18 \%$ in data on 22 Latin American countries covering the period 1980-1997. Similar results are obtained by Fink et al. (2002), Ros (2003), and Li and Xu (2004) using various data sets.

Other empirical studies using worldwide data sets, in particular, Ros (1999) and McNary (2001), indicate that privatization has no or even a neg- 
ative impact on fixed-line deployment. ${ }^{7}$ Nevertheless, both authors insist on the role played by independent regulators in the privatization process, a feature that neither of them includes in their investigations. The importance of this issue is highlighted by Wallsten (2001) and Gutierrez (2003) who find that privatization coupled with the existence of an independent regulator results in larger gains in terms of network expansion. Fink et al. (2002) and Ros (2003) also find that the impact of privatization and competition reforms is enhanced by the creation of a separate regulator. As to the impact of privatization on efficiency, it is found that it is similarly affected by the presence of an independent regulator (Wallsten, 2001, Gutierrez, 2003). ${ }^{8}$

There is an emerging yet limited empirical literature focusing on the determinants of sectoral reforms in infrastructure industries and this literature has been so far mainly concerned with political factors. Using telecommunications data for the period 1990-1998 on a panel of countries chosen worldwide, $\mathrm{Li}$ and $\mathrm{Xu}$ (2002) and Li et al. (2005) explore the political economy of liberalization, privatization, and regulatory reforms. ${ }^{9}$ In both studies, countries with stronger pro-reform interest groups, namely, financial actors and urban consumers, are more likely to implement reforms in more democratic environments. Li and Xu (2002) find that less democratic countries are more likely to maintain the public sector monopoly when the fiscal deficit is high. In addition, Li et al. (2005) find that reforms are less likely to be implemented in countries where incumbent operators have already sunk large investments since these operators have strong incentives to oppose the reforms.

Closer to our work, Gual and Trillas (2006) are, to the best of our knowledge, the first to consider both the determinants of the reforms, in particular, to highlight the role of entry and regulatory policies, and the impact of the

\footnotetext{
${ }^{7}$ For an analysis of privatization policies across the world, see Bortolotti and Siniscalco (2004).

${ }^{8}$ Some details of the private transactions are also found to play an important role in network deployment. See Wallsten (2000) and Li and Xu (2004) for the effects of exclusivity periods and Ros (2003) for the effects of the price cap regulatory regime.

${ }^{9}$ Liberalization reforms are measured by an index computed as the average of six indicators describing the market environment (multiple-player environment, pro-competition initiatives, and interconnection policy) in the fixed-line and cellular segments. Privatization concerns the fixed-line incumbent while regulatory reforms account for tariff policies and the degree of autonomy and transparency of regulation in the fixed-line and cellular segments.
} 
reforms on network deployment. They use a Two-Stage-Least-Squares estimation technique to fit 1998 cross-sectional data on 37 countries. ${ }^{10}$ Though their results are not always robust, these authors find some preliminary evidence that competition policies have a positive impact on network deployment and that regulatory independence has a negative effect on productivity. With regard to the determinants of reforms, they find that countries with interventionist traditions have fewer liberalization policies and that the larger the size of the incumbent and the lower the protection of investors, the more prone a country is to create an independent regulator.

We extent the work of Gual and Trillas (2006) in two ways. First, we analyze in a more disaggregated manner the role of major policies that have been used to reform the telecommunications sector. More specifically, we attempt to estimate the effect of the level of competition in the digital and analogue cellular segments, and in the local fixed-line segment, the effect of the creation of a separate regulator, and the effect of privatization of the fixed-line incumbent. Second, we provide an interpretation of some of our results as tests of a series of hypotheses derived from the theoretical literature on telecommunications reform. These hypotheses are mostly concerned with the institutional and financial endowments of a country that have been emphasized in the literature as being important drivers of infrastructure industries reforms in developing countries. This approach allows us therefore to evaluate the indirect impact, through the reforms selected by the governments, of these country-specific features on infrastructure deployment.

\section{Data}

We have constructed a time-series-cross-sectional (TSCS) data set containing time-varying information on 86 developing countries for the period 1985-

\footnotetext{
${ }^{10}$ Entry policies relate to investment conditions imposed on entrants, average number of cellular providers, number portability, carrier selection, carrier pre-selection, and local loop unbundling availability. Regulatory policies have to do with licensing, interconnection, tariffs, scarce resources, universal service, the funding structure, the appointment process of regulators, the length of the term, the reporting process, the year of establishment of effective operation, and the incumbent capital ownership.
} 
1999. ${ }^{11}$ These data have been organized in variables regrouped in five categories, namely, "Telecommunications deployment," "Telecommunications reforms," "Institutional environment and risk indices," "Cost of public funds," and "Other variables and instruments." The list of the countries in four regions included in the data set, the designation of each of the variables, the data sources, some standard summary statistics, and some information on the history of the introduction of analogue and digital cellular technologies in the country regions are given in the supplemental document available from the authors upon request. To facilitate the discussion of the various variables used in the analysis, we give in Table 1 below their acronyms and designation.

The deployment of telecommunications infrastructure is captured in a variable that gives the number of telephone lines per 100 inhabitants that connect the subscribers' terminal equipment to the PSTN. ${ }^{12}$ Telecommunications reforms are represented by variables that give the number of competitors in the analogue and digital cellular segments, variables that indicate whether competition prevails in the fixed-line local segment and whether a separate telecommunications regulator has been created, and a variable that gives the $\%$ of the fixed-line incumbent's assets sold to private investors. The extent of competition in the analogue and digital cellular markets is captured in a four-category variable that specifies the number of licenses issued in these segments, that is, no license, one license (monopoly), two licenses (duopoly), or more (high competition). As to the fixed-line market, we focus on competition in the local segment as this is the one that has historically constituted a bottleneck. ${ }^{13}$ Moreover, we do not differentiate between a duopoly situation and a high competition situation in the fixed-line local segment since there are very few countries in our data set that have actually attributed more than two licenses to this segment.

\footnotetext{
${ }^{11}$ Selectivity bias should not be a concern in our data set. First, our panel includes some countries that have reformed and some that haven't. Second, firms do not appear as having control over the regulatory regime under which they operate. On the one hand, firms with poor performance may be subject to reforms. On the other hand, the government may decide to reform well performing sectors that deliver high license fees. For empirical evidence on such a positive relationship between firms' performance and the introduction of reforms, see, e.g., Ross (1999).

${ }^{12}$ Public Switched Telephone Network.

${ }^{13}$ Hence, we do not consider competition in the long distance and international segments.
} 


\section{List of variables and designation*}

\begin{tabular}{|c|c|}
\hline Variable & Designation \\
\hline $\begin{array}{l}\text { TELECOMMUNICATIONS DEPLOYMENT } \\
m l\end{array}$ & Fixed-line deployment \\
\hline TELECOMMUNICATIONS REFORMS & \\
\hline$a c$ & Cellular competition (analogue) \\
\hline counter_ana & Counter (analogue) \\
\hline$d c$ & Cellular competition (digital) \\
\hline counter_dig & Counter (digital) \\
\hline$l c$ & Fixed-line competition (local) \\
\hline$r$ & Separate regulator \\
\hline$p$ & Privatization \\
\hline $\begin{array}{l}\text { INSTITUTIONAL ENVIRONMENT AND RISK INDICES } \\
\text { corruption }\end{array}$ & Corruption \\
\hline institutional & Institutional index \\
\hline democracy & Democracy index \\
\hline risk & Risk index \\
\hline COST OF PUBLIC FUNDS & \\
\hline debt & Total debt service \\
\hline $\operatorname{tax}$ & Net taxes on products \\
\hline aid & Aid per capita \\
\hline OTHER VARIABLES AND INSTRUMENTS & \\
\hline density & Population density \\
\hline rural & Rural population \\
\hline import & Imports \\
\hline staff & Telecommunications staff \\
\hline checks & Checks and balances \\
\hline english & English legal origin \\
\hline french & French legal origin \\
\hline protest 80 & Share of protestant (1980) \\
\hline latitude & Latitude \\
\hline school 80 & Average schooling years (1980) \\
\hline ethno & Ethnolinguistic fractionalization \\
\hline africa & Africa \\
\hline land & Crop and forest land \\
\hline polcon & Political constraints \\
\hline free_press & Free press \\
\hline ethnic & Ethnic tensions \\
\hline rule & Law and order \\
\hline
\end{tabular}

*A detailed description of these variables is provided in the supplemental document.

The institutional environment and risk indices indicate how corrupt the government is and how strong its ability to commit to announced policy is. ${ }^{14}$

${ }^{14}$ To capture the quality of the institutional environment, we use an index represented by the variable institutional (see Table 1). The variable institutional is built by summing five institutionalization variables the values of which are given in the supplemental document. These variables capture the degree of corruption in the political system, the quality of the bureaucracy and its capacity to govern without drastic changes in policies or interruption of service, law and order as a measure of the strength of the legal system and of the popular observance of the law, the risk of expropriation of private investments 
These indices are constructed from variables measuring the degree of corruption, the quality of the institutional framework, and the level of democracy in the country. ${ }^{15}$ Corruption includes actual and potential influence of the political system in the form of excessive patronage, nepotism, job reservations, favors for favors, secret party funding, and close ties between politicians and businesses. The quality of the institutional framework is captured by a variable that is calculated as the unweighted sum of variables reflecting government integrity, the efficiency of bureaucracy, the strength of courts and their capacity to enforce decisions, and government commitment credibility, in particular, the extent to which asset expropriation and contract repudiation is used by the government. The level of democracy is captured in a variable whose value is found by subtracting an index of autocracy from an index of democracy. The risk index is measured by a variable computed as the average of three series corresponding to economic, financial, and institutional risks. Higher values of these institutional environment and risk indices reflect a "better" overall institutional environment and a lower risk.

The cost of public funds is captured in variables measuring the value of debt service and net taxes on products as a proportion of respectively the gross national income (GNI) and the gross domestic product (GDP) and aid per capita, all expressed in 2000 USD. ${ }^{16}$ These variables are chosen because of the relationships between them which can be explained as follows. For a given tax system, increases in debt force the government to increase its revenue requirement by borrowing more or by increasing taxation. Hence, one can expect a positive relationship between debt and the cost of public funds. ${ }^{17}$ Net taxes on products capture a type of commodity taxation which has been introduced in recent years providing developing countries with a more effective instrument for raising revenues than other indirect taxation mechanisms such as taxes on profits. These relatively efficient taxes and aid

\footnotetext{
by forced nationalization, say, and the risk that the government modifies a contract by repudiation, postponement, or scaling down. Higher values of this index reflect a better overall institutional environment.

${ }^{15}$ Laffont (2005) evokes the idea of corruption and democracy being negatively correlated.

${ }^{16}$ The cost of public funds is commonly viewed as the deadweight loss due to distortionary taxation that the government has to rely on to collect these funds.

${ }^{17}$ We should note that here we are not making inferences about the variables in levels. Indeed, a given level of the cost of public funds results from a complex interaction among multiple tax instruments and as such it may coexist with different debt levels.
} 
perceived by the government may have a direct impact on the government funding requirements and can be expected to be negatively correlated with the cost of public funds. ${ }^{18}$ Since it takes time for changes in debt or aid to have an effect on the tax system and for taxes on products to be settled, we use lagged values of these variables in the parameterization of the cost of public funds.

Variables under the heading of "Other variables and instruments" are those that measure other factors that are deemed relevant for our estimation of the determinants and the impact of the reforms. The "variables" part includes the population density, the $\%$ of the population that is rural, imports as a proportion of GDP, full time fixed-line and cellular telecommunications staff as a proportion of total population, and the number of checks and balances in the political system. In addition to being an indicator of the division of power in the political system, in as so far as it is informative of the political stability of the country, the checks and balances variable also captures the level of the (social) discount rate in the country. More specifically, the higher the discount rate, i.e., the higher the valuation of the future by agents, the higher the number of checks and balances indicating a "better" mode of functioning of the political process.

The "instruments" part includes a set of variables reflecting various country specific features that might improve the explanatory power of the estimated models. This set includes variables concerning some aspects related to the origin (English or French) of the legal system, the importance of protestants in the population (\% in 1980), the country's latitude (in absolute value), the country's level of literacy (average schooling years in the population over 25 in 1980), and the ethno-linguistic fractionalization of the country. It also includes variables that specify whether the country belongs to Sub-Saharan Africa, the importance of crop and forest land in the country (ratio to total land), whether there are significant political obstacles to policy changes in the country, the quality of the media's legal environment, the degree of tension attributable to race, nationality, or language, and the strength of the legal system and the public observance of the law.

\footnotetext{
${ }^{18}$ This is a different argument than that of aid conditionality. For example, aid conditionality may not be effective when the recipient country does not want to reform (see Ghosh Banerjee and Rondinelli, 2003).
} 


\section{Empirical analysis}

To empirically investigate the determinants of the telecommunications reforms and the impact of these reforms on network expansion, we run a set of regressions with the dependent variable representing either a reform policy or a measure of infrastructure deployment. Prior to specifying the regressions to be estimated, however, we perform some tests for the existence of two-way causal relationships between the variables representing telecommunications reforms and those representing fixed-line network deployment. ${ }^{19}$ These tests, of the Granger-causality type developed in Holtz-Eakin et al. (1988), allow us to obtain a set of potential explanatory variables to be used in the specification of the regressions. ${ }^{20}$

In the reform regressions, the independent variables have been chosen so as to allow us to test some hypotheses derived from the recent theoretical literature on the determinants of the reforms. These hypotheses are concerned with the role of corruption and the cost of public funds in the decisions to introduce competition and privatize state-owned incumbents. They are also concerned with the influence that the government's ability to commit, the return on investment, and the discount factor have on the decision to create a separate regulator. In the regressions that aim to explain infrastructure deployment, the latter being measured by a variable of fixed-line network expansion, we use, among other explanatory variables, indicators of the telecommunications reforms.

For the estimation, we apply two different techniques according to the nature of the dependent variable. For the regressions involving a discrete dependent variable, we use the group duration methodology developed in Beck et al. (1998). This is the case when the dependent variable is an indicator of competition in the analogue or digital cellular segments, in the local fixed-line segment, or of the existence of a separate regulator. For the regressions involving a continuous dependent variable, we use the System

\footnotetext{
${ }^{19}$ These tests also shed some light on the issue of endogeneity of reforms to network expansion, an issue that has been raised in the literature. See Ros (1999) and Gutierrez (2003) on the endogeneity of competition in the local, long distance, and international fixed-line service, and of the privatization of the incumbent operator. Endogeneity of regulation is discussed in Gutierrez (2003) and Ros (2003).

${ }^{20}$ The reader is referred to Gasmi et al. (2006) for details on the implementation of these tests.
} 
Generalized Method of Moments (SYS-GMM) developed by Arellano and Bond (1991) for panel data and applied by Beck and Katz (2004) to TSCS data. $^{21}$ This technique is used when the dependent variable represents the privatization reform policy or the deployment of fixed-line network.

This empirical section is organized as follows. We first describe the basic econometric equations specified and the methods used to estimate them. Second, we present the results of a preliminary inspection of the data the purpose of which is to search for empirical evidence of causal relationships between the telecommunications reforms and fixed-line deployment variables. Third, we discuss the theoretical hypotheses on the determinants of the reforms that we test in our regressions. Fourth, we move on to presenting the results of our regressions of the determinants of the reforms. Fifth, we synthesize the empirical information contained in the results pertaining to the simultaneous relationship between reforms and fixed network expansion. Finally, we summarize our findings on the institutional and economic environment determinant of reforms.

\subsection{Econometric specification and estimation methods}

For the regressions in which the reform dependent variables are discrete, we fit the data by applying a grouped duration methodology that allows us to explore the presence of temporal dependence. ${ }^{22}$ This methodology consists in using the complementary log-log (CLOGLOG) estimation technique with the discrete dependent variables capturing the elapsed time until the reform and with $d$ temporal dummies, temp $d, d=1,2, \ldots, 14$, capturing the time since the most recent event. ${ }^{23}$ Since including the temporal dummies may introduce multicollinearity, we first test if they are needed by means of a

\footnotetext{
${ }^{21}$ See also Arellano and Bover (1995) and Blundell and Bond (1998).

${ }^{22}$ The presence of temporal dependence in TSCS discrete regressions results in a violation of the assumption of independent observations which leads to an underestimation of their variability. In our context, the number of years elapsed between an event, e.g., the issuing of a license in the case of competition variables or the creation of the regulatory authority in the case of the variable that indicates the existence of a separate regulator, and the start of the sample or the previous event seems likely to influence the results.

${ }^{23}$ The dependent variable takes on the value 1 in year $t$ if one license or more has been issued sometime in year $t$, in the case of the competition variables, or if the regulatory agency has been separated from and is not directly controlled by a ministry or a utility sometime in year $t$, in the case of the variable indicating the existence of a separate regulator, and 0 otherwise. The temporal dummies are created by first constructing a variable marking the length of the sequence of zeros that precede the current observation of the dependent variable.
} 
likelihood ratio test of the hypothesis that the observations are temporally independent, i.e., that $t e m p_{d}=0$ for all $d$.

An econometric issue which is particularly relevant in our modeling context is that of the occurrence of multiple events in the series indicating competition in the analogue and digital cellular segments. Omitting to explicitly model multiple events amounts to assuming that first, second, and subsequent events are independently distributed. It is, however, unlikely that an event such as the issuing of a license is independent of the timing and the number of licenses previously issued in the same segment. To model multiple events, we include a variable, counter, that counts at a given year the number of similar events that occurred in the previous years. ${ }^{24}$

In the case of a discrete reform dependent variable, we then specify the following model:

$$
\begin{gathered}
r_{i t}^{*}=\phi+\mathrm{x}_{i t}^{\prime} \varphi+\sum_{d=1}^{T-1} \text { temp }_{d, i t}+\text { counter }_{i t}+\omega_{i t} \\
i=1,2, \ldots, N ; \quad t=1,2, \ldots, T ; \quad r_{i t}=\left\{\begin{array}{lll}
1 & \text { if } & r_{i t}^{*} \geq 0 \\
0 & \text { if } & r_{i t}^{*}<0
\end{array}\right.
\end{gathered}
$$

where the indices $i$ and $t$ refer to the country and the year, respectively, $r_{i t}^{*}$ is an unobserved latent variable, $r_{i t}$ is a dichotomous variable representing the reform, $\phi$ is a scalar parameter, $\mathrm{x}_{i t}$ is a vector of regressors, $\varphi$ is the associated vector of parameters, and $\omega_{i t}$ is a disturbance term. The vector of regressors $\mathrm{x}_{i t}$ includes the population density, the $\%$ of the population that is rural, and some variables introduced for the purpose of testing a series of hypotheses derived from the theoretical literature on the determinants of reforms. ${ }^{25}$ For the data set used in the analysis $N=86$, the number of developing countries in the sample, and $T=15$, the number of years of observation in the period 1985-1999.

\footnotetext{
${ }^{24}$ The counter variable takes on the value 0 in year $t$ if no license has been issued in $t-1$ or earlier, 1 if one license has been issued in $t-1$ or earlier, 2 if two licenses have been issued in $t-1$ or earlier, and 3 if three or more licenses have been issued in $t-1$ or earlier. In practice, this variable is noted counter_ana in the regression concerning competition in the analogue cellular segment and counter_dig in the one concerning competition in the digital cellular segment.

${ }^{25}$ The vector of regressors $\mathrm{x}_{i t}$ is expressed in first differences in order to eliminate sources of unobserved fixed heterogeneity.
} 
Some of the regressors included in $\mathrm{x}_{i t}$ may in fact be endogenous which would lead to inconsistent estimators. ${ }^{26}$ To circumvent this difficulty, we specify an additional equation for each of the endogenous regressors and use Full Information Maximum Likelihood (FIML) to estimate the system. ${ }^{27}$ More specifically, FIML is used to estimate the simultaneous system composed of (1) and the equation

$$
v_{i t}=\vartheta+\mathrm{w}_{i t}^{\prime} \gamma+\mathrm{z}_{i t}^{\prime} \delta+\eta_{i t}
$$

where $v_{i t}$ is a component of the vector $\mathrm{v}_{i t}$ of (continuous) endogenous regressors in $\mathrm{x}_{i t}, \vartheta$ is a scalar parameter, $\mathrm{w}_{i t}$ is a vector of exogenous regressors in $\mathrm{x}_{i t}, \gamma$ is the associated vector of parameters, $\mathrm{z}_{i t}$ is a vector of instruments, $\delta$ is the associated vector of parameters, and $\eta_{i t}$ is a disturbance term.

For the regressions in which the reform dependent variable is continuous, we fit the data by using the SYS-GMM method for dynamic panels as applied to TSCS data. ${ }^{28}$ However, with a non stationary dependent variable, the dispersion of the value of the coefficient in an autoregressive process of order one found with different asymptotically equivalent methods is known to often exceed its standard errors. Hence, we first investigate the stationarity of our dependent variables. We find that these variables are stationary in first differences and hence continue our analysis with these series transformed in first differences. ${ }^{29}$

In the case of a continuous reform dependent variable, we then specify the following dynamic autoregressive model:

$$
y_{i t}=\alpha_{0}+\alpha_{1} y_{i t-1}+\mathrm{x}_{i t}^{\prime} \beta+\mu_{i}+\epsilon_{i t}
$$

where $i=1,2, \ldots, N, t=1,2, \ldots, T, y_{i t}$ is a one-dimensional variable rep-

\footnotetext{
${ }^{26}$ Endogeneity might stem from say competition having an effect on how corrupt the government is (see Bliss and Di Tella, 1997, and Laffont and N'Guessan, 1999) or the creation of a separate regulator affecting the level of network expansion and the size of the telecommunications staff.

${ }^{27}$ Although FIML can be used to perform an exogeneity test, it becomes computationally unfeasible as the number of regressors included as endogenous grows. We use then the Two Stage Conditional Maximum Likelihood (2SCML) estimator derived by Rivers and Vuong (1988) to perform exogeneity tests since it allows the presence of multiple potentially endogenous regressors. For more on 2SCML exogeneity tests, see the supplemental document available from the authors.

${ }^{28}$ The dynamic nature of our data has been confirmed by Lagrange multiplier tests.

${ }^{29}$ Details on the stationarity tests can be found in Gasmi et al. (2006) and the results obtained for this paper are available from the authors upon request.
} 
resenting the continuous dependent variable (fixed-line deployment or privatization level), $\alpha_{0}$ and $\alpha_{1}$ are scalar parameters, $\mathrm{x}_{i t}$ is a vector of regressors, $\beta$ is the associated vector of parameters, $\mu_{i}$ is a country-specific fixed factor, and $\epsilon_{i t}$ is a disturbance term. ${ }^{30}$ For the fixed-line deployment regression, the vector of regressors $\mathrm{x}_{i t}$ includes the institutional and democracy indices, the population density, and the $\%$ of the population that is rural. It also contains the indicators of the telecommunications reforms. For the privatization regression, this vector of regressors contains the two population variables and the variables that are used to test the hypotheses derived from the theoretical literature on the determinants of reforms.

In our context, endogeneity problems seem likely to arise in the estimation of equation (3). One may argue, for example, that privatization might be used to signal commitment towards policy reforms contributing to the reduction of risk ratings. Moreover, it has been argued that privatization of public utilities may open the door to more corruption (Martimort and Straub, 2006). To find appropriate instruments we use a standard approach that consists in taking lagged variables in levels as a set of potential instruments and selecting appropriate lag lengths by investigating whether the disturbance term is serially uncorrelated. ${ }^{31}$

\subsection{Causality}

Table 2 below summarizes the results of the Holtz-Eakin et al. (1988) causality testing procedure applied to the telecommunications reforms and fixedline deployment variables. More specifically, these tests allow us to conclude on the existence of a causal relationship of a Granger type between the variables that represent competition in the analogue cellular segment, $a c$, competition in the digital cellular segment, $d c$, competition in the fixed-line local segment $l c$, the creation of a separate regulator, $r$, and privatization, $p$, on the one hand, and the variable that proxies the fixed-line deployment, $m l$,

\footnotetext{
${ }^{30}$ The standard assumptions $\mathrm{E}\left(\mu_{i}\right)=0, \mathrm{E}\left(\epsilon_{i t}\right)=0, \mathrm{E}\left(\epsilon_{i t} \mu_{i}\right)=0$, and $\mathrm{E}\left(y_{i 1} \epsilon_{i t}\right)=0$ are made. The fixed-line deployment series is transformed in logs to minimize heteroskedasticity and influential outliers problems and the vector of regressors $\mathrm{x}_{i t}$ is taken in first differences to eliminate any sources of unobserved fixed heterogeneity.

${ }^{31}$ For a detailed description of how this approach is implemented, see Gasmi et al. (2006).
} 
on the other hand. ${ }^{32}$

\begin{tabular}{|c|c|c|c|c|c|}
\hline \multicolumn{6}{|c|}{$\begin{array}{c}\text { Table } 2 \\
\text { Causal relationships }\end{array}$} \\
\hline & $a c$ & $d c$ & $\overline{l c}$ & $r$ & 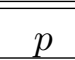 \\
\hline $\begin{array}{l}\text { reform } \rightarrow \text { fixed-line deployment } \\
\text { fixed-line deployment } \rightarrow \text { reform }\end{array}$ & $\begin{array}{l}\text { Yes } \\
\text { No }\end{array}$ & $\begin{array}{l}\text { Yes } \\
\text { Yes }\end{array}$ & $\begin{array}{l}\text { No } \\
\text { Yes }\end{array}$ & $\begin{array}{l}\text { Yes } \\
\text { Yes }\end{array}$ & $\begin{array}{l}\text { Yes } \\
\text { No }\end{array}$ \\
\hline
\end{tabular}

This table shows that the telecommunications reforms Granger-cause fixed-line deployment except when using the variable of competition in the fixed-line local segment as the reform variable. Examining the reverse causality, we find some evidence of one that runs from the fixed-line deployment variable to the telecommunications reforms variables although slightly weaker. More specifically, the fixed-line deployment variable causes the variable of competition in the digital cellular segment, the variable of competition in the fixed-line local segment, and the variable that indicates the creation of a separate regulator. However, we do not find any empirical evidence that would suggest that the fixed-line deployment variable causes the variable of competition in the analogue cellular segment and the variable of privatization.

In addition to bringing some empirical evidence on the existence of causal relationships between reforms and infrastructure deployment variables, these Granger tests provide us with invaluable information on the dynamics of these relationships when they are found to exist. In the end, these tests allow us to select potential variables, and their precise lag structure, to be included as regressors in the regressions that are used to model the relationship between reforms and network deployment. ${ }^{33}$

\subsection{Determinants of reforms: Testable hypotheses}

The literature on the factors that influence the decision to reform the telecommunications sector by introducing competition has emphasized the role of corruption of the political system and the cost of public funds. Emerson

\footnotetext{
${ }^{32}$ The estimations on which these Granger-causality tests are based are available from the authors upon request.

${ }^{33}$ Following Holtz-Eakin et al. (1988), we use variables lagged one, two, and three periods in the Granger causality tests.
} 
(2006) develops a model where rent seeking firms agree to pay bribes to policy makers to limit market entry. One of the equilibria obtained is characterized by low (high) levels of corruption combined with high (low) levels of competition. Under the assumption that data reflect equilibrium sate, this suggests the following hypothesis:

Hypothesis 1: Countries with relatively high corruption will tend to introduce less competition.

Following a normative approach, Auriol and Picard (2004) develop a model where it is optimal to foster competition in infrastructure industries when the cost of public funds is low. In our context, this argument translates into the hypothesis that follows:

Hypothesis 2: Countries with a relatively high cost of public funds will tend to introduce less competition.

Turning to the reform which involves the creation of an independent regulator, the literature has pointed to the role of government commitment, return on investment, and the discount factor. Drawing on a framework developed for analyzing the decision to create independent central banks, Evans et al. (2005) claim that in infrastructure industries government commitment and regulatory independence are substitutes. Moreover, these authors argue that regulatory independence becomes more necessary to alleviate underinvestment when the return on investment and the discount factor are high. ${ }^{34}$ These arguments translate into the following hypothesis:

Hypothesis 3: Countries with relatively low government commitment, large returns on investment, and high discount factors will tend to create an independent regulator.

Among the determinants of the privatization reform in infrastructure sectors discussed in the literature, we have focused on the role of corruption of

\footnotetext{
${ }^{34}$ Evans et al. (2005) show how delegating pricing decisions to a sufficiently pro-industry regulator, i.e., whose preferences differ from those of the government, can alleviate the under-investment problem in the absence of regulatory commitment. In addition, if investment in a regulated sector is crucial for the development of a country, it becomes then necessary to provide a mechanism to alleviate under-investment. These authors also find evidence that when agents attach a high value to the future due, for example, to political stability or low interest rates, the welfare enhancing properties of the independent regulator become more evident.
} 
the political system and the cost of public funds. Laffont (2005) develops a positive theory of privatization where, for sufficiently low levels of corruption, as corruption increases the private gains of politicians from privatization are larger than those obtained with a public firm and dominate the social costs of privatization. However, for very large levels of corruption, it is necessary to leave the control of the firm to private shareholders, and in these circumstances, the private gains of politicians cannot compensate for the rents appropriated by private investors. An implication of this theory is then that at low (high) levels, increasing levels of corruption should influence positively (negatively) the decision to privatize. In our context, this implication translates into the hypothesis that follows:

Hypothesis 4: Countries with sufficiently small or high levels of corruption will tend to privatize less.

Returning to the normative approach, Auriol and Picard (2004) find that when the government does not fully capture the expected profit of the privatization transaction, privatization improves social welfare for intermediate values of the cost of public funds, but state ownership is preferred for low or high values. Since developing countries have typically medium to large levels of the cost of public funds, the latter should negatively influence the privatization decision. ${ }^{35}$ The implication then is that when public firms in the infrastructure sectors are sold at a discount because of a high country risk rating, a government in need for cash should keep the profitable ones. We translate these arguments into the following hypothesis:

Hypothesis 5: Countries with a relatively high cost of public funds and a high risk will tend to privatize less.

\subsection{Determinants of reforms: Estimation}

We now make use of regression analysis to investigate the determinants of the telecommunications reforms. We first consider the econometric specifications with a discrete reform dependent variable which are used to model the introduction of competition in the cellular (analogue and digital) and

\footnotetext{
${ }^{35}$ Using a normative approach, Warlters (2004) also finds that a decrease in the cost of public funds may induce infrastructure privatization in developing countries.
} 
fixed-line (local) markets, and the creation of a separate regulator. These models are estimated using CLOGLOG and FIML when exogeneity turns out to be rejected. Then, we consider the specification with a continuous reform dependent variable which is used to model privatization. This model is estimated using SYS-GMM and possible endogeneity of some regressors is accounted for. In both types of specifications, the main regressors are drawn from the set of variables that have "passed" the causality tests discussed in section 4.2 and so as to permit the testing of the hypotheses discussed in section 4.3.

\section{Determinants of competition (cell and fixed) and of decision to create a regulatory authority}

Tables A1 through A4 given in the appendix display the estimation results obtained by applying the grouped duration (robust cluster) methodology to the regressions with, respectively, the variable competition in the analogue cellular segment $\left(a c_{i t}\right)$, competition in the digital cellular segment $\left(d c_{i t}\right)$, competition in the fixed-line local segment $\left(l c_{i t}\right)$, and creation of a separate regulator $\left(r_{i t}\right)$ as the dependent variable. ${ }^{36,37}$ When CLOGLOG is applied (see the columns with the heading "CLOGLOG" in the tables), these tables show the parameter estimates corresponding to the indicated explanatory variables without and with temporal dummies, the value of the log of the pseudo-likelihood, "Log-likelihood," a likelihood ratio statistic for testing the validity of the temporal dummies, "Temporal dummies LR," and the number of observations actually used in the estimation, "Obs." 38

In the cases where endogeneity problems arise, FIML, more specifically 2SCML, is applied. We indicate the instruments that have been excluded in the first-stage, "Instruments," the squared partial correlation coefficient between the excluded instruments and the endogenous variable, "Partial $R^{2}$," the value of the $\mathrm{F}$ statistic for testing the joint significance of the instruments

\footnotetext{
${ }^{36}$ Note that the independent variables are in first differences.

${ }^{37} \mathrm{~A}$ modified Wald test for groupwise heteroskedasticity under the null of homoskedasticity rejects at the $1 \%$ significance level in all the regressions presented in Tables A1-A4. Hence, standard errors are adjusted for intragroup correlation. The mean variance inflator factor is also calculated in all the regressions and the values obtained always remain smaller than 3.

${ }^{38}$ In all the tables presented in this paper, we indicate the significance at the $10 \%, 5 \%$, and $1 \%$ confidence level by the subscripts, $*, * *$, and $* * *$ respectively.
} 
excluded in the first stage regression, "F," the Sargan statistic for testing the validity of the excluded instruments, "Sargan," the squared correlation coefficient between observed and fitted first-stage values of the dependent variable, " $R_{O L S}^{2}$ " the estimated correlation coefficient between the disturbances of the first and second stage regressions ( $\omega i t$ and $\eta_{i t}$ from equations (1) and (2)) that signals whether the tested variable is endogenous, "Rho," and the value of the subsequent exogeneity test statistic, "Exogeneity." 39

Let us first examine the CLOGLOG estimation results of the models without and with temporal dummies exhibited in Tables A1-A4. Comparing these two types of models, we see from the values of the Temporal dummies LR statistic that temporal independence is rejected in the models of competition in the digital cellular segment and creation of a separate regulator. This suggests that the time elapsed between a given reform and the previous one or the beginning of the sample influences the outcome in the case of the introduction of competition in the digital cellular segment and the creation of a separate regulator, but not in the cases of the introduction of competition in the analogue cellular and fixed-line local segments.

Regarding the presence of multiple events in the series describing the introduction of competition in the analogue and digital cellular segments indicated by the variables counter_ana and counter_dig respectively, the following obtains. The regressor counter_ana has a significant negative impact on the variable competition in the analogue cellular segment (Table A1). ${ }^{40}$ However, the regressor counter_dig does not have a significant impact on the variable competition in the digital cellular segment once temporal dependence is corrected for (Table A2, Model E). Hence, the number and frequency of licenses previously granted in the analogue cellular segment has a negative impact on the decision to grant a license, that is, the second and

\footnotetext{
${ }^{39} \mathrm{~A}$ value of $\mathrm{F}$ over 10 is typically sufficient for identification in the presence of one endogenous regressor. An $R_{O L S}^{2}$ over $10 \%$ is also required for identification. As to the Sargan test, we have adapted it to these discrete regressions. The validity of instruments is checked wit a a Wald test.

${ }^{40}$ Given the history of the introduction of cellular technology (analogue followed by digital), incorporating cellular competition in digital, $d c$, as a regressor for cellular competition in analog creates an endogeneity problem that adds substantial complexity to the estimation of this discrete model. Nevertheless, the counter variable, which has been found to have a significant negative effect (see Table A1), gives a reasonable indication of the role that digital has played in the evolution of the cellular market.
} 
subsequent licenses are not issued independently of the first one. ${ }^{41}$ In contrast, the structuration of previous licenses does not appear as having an effect on the decision to grant a license in the digital cellular segment.

Given that some explanatory variables in these regressions with a discrete reform dependent variable may potentially be endogenous, we perform exogeneity tests by applying the 2SCML (cluster-robust) technique to the best of the two models, the one without temporal dummies and the one with. ${ }^{42}$ In fact, the best model is the one without dummies if temporal dependence is rejected and the one with temporal dummies if it isn't. From Tables A1A4, we see that the final modeling choices for the dependent variables are Model $\mathrm{A}$ for $a c$ and Model $\mathrm{H}$ for $l c$, both of these models without temporal dependence, and Model $\mathrm{E}$ for $d c$ and Model $\mathrm{L}$ for $r$, both with temporal dependence.

Exogeneity is rejected in three cases. ${ }^{43}$ The fixed-line deployment variable $\left(\Delta \log \left(m l_{i t-1}\right)\right)$ is endogenous to the variable of competition in the digital cellular segment according to both the individual test at the $10 \%$ level and the joint test at the $5 \%$ level. The corruption variable $\left(\Delta\right.$ corruption $\left._{i t}\right)$ is endogenous to the variable of competition in the fixed-line local segment when tested both separately at the $10 \%$ level and jointly at the $1 \%$ level. Finally, in Table S5, the institutional index ( $\Delta$ institutional $\left._{i t}\right)$ is endogenous to the decision of creating a separate regulator when test both separately at the $10 \%$ level and jointly at the $5 \%$ level. $^{44}$

\footnotetext{
${ }^{41}$ This is consistent with the fact that during the period under study many countries maintained a monopoly in the analogue cellular segment with the unique license often owned by the fixed-line incumbent.

${ }^{42}$ Tables S2-S5 given in the supplemental document to this paper report the results of these exogeneity tests performed on each of the potentially endogenous variables separately and then jointly. In addition to containing some items already described for Tables A1-A4 in the appendix, these tables include a Shea's square partial correlation that takes into account the inter-correlation among instruments when more than one variable is being tested at a time, "Shea's partial $R^{2}$." Note that the Shea's Partial $R^{2}$ is more informative than the Partial $R^{2}$ in the presence of multiple potentially endogenous regressors. In such a context, a large partial $R^{2}$ and a small Shea's partial $R^{2}$ are interpreted as indicating that the model is not identified.

${ }^{43}$ The Sargan statistic confirms the validity of instruments. In addition, there is no problem of identification as is shown by an F statistic always superior to 10 in at least one of the proposed testing configurations (separate or joint testing of the endogenous regressors). The Shea Partial $R^{2}$ is severely downsized as compared to the Partial $R^{2}$ only in the joint exogeneity test performed in Table S5 of the supplemental document. Nevertheless, this joint test is consistent with the results of the individual tests shown in the same table.

${ }^{44}$ These results can be seen from Tables S3-S4 of the supplemental document.
} 
For these cases where exogeneity is rejected, the FIML estimation results are also reported in Tables A2-A4 and kept for the subsequent regressions in which alternative explanatory variables are added. ${ }^{45}$ We observe that the correlation coefficient Rho and the Exogeneity statistic found with FIML confirm the 2SCML results rejecting the exogeneity of the instrumented variables. $^{46}$ In the regressions corresponding to the variable of competition in the digital cellular segment (Table A2), we see that the variable of fixed-line deployment $\left(\Delta m l_{i t-1}\right)$ becomes significant at the $1 \%$ level once instrumented in Models $\mathrm{F}$ and $\mathrm{G} .{ }^{47}$ In the regressions of the variable competition in the fixed local segment (Table A3), the variable of corruption $\left(\Delta\right.$ corruption $_{i t}$ ) changes from a positive and significant effect in Model $\mathrm{H}$ to a negative and significant effect once this variable is instrumented in Model $\mathrm{J}{ }^{48}$ Finally, in the regressions that model the decision to create a separate regulator (Table A4), the institutional index ( $\Delta$ institutional $_{i t}$ ) changes from having a non significant effect in Model L to a positive and significant effect at the $5 \%$ level once this variable is instrumented in Model M. ${ }^{49}$

We now turn to the empirical evidence concerning the hypotheses on the determinants of reforms discussed in section 4.3. Hypothesis 1 regarding the role of corruption is only partially confirmed by our estimation results. We do find some empirical support to it since the variable corruption is incorporated in the institutional index $\left(\Delta\right.$ institutional $\left._{i t}\right)$ and the latter, as can be seen from Table A1, has a positive and significant impact on the decision to introduce competition in the analogue cellular segment (Models A and C). ${ }^{50}$

\footnotetext{
${ }^{45}$ The CLOGLOG model is kept only in the case of competition in the analogue cellular segment where we didn't find evidence of endogeneity. The reported estimates with CLOGLOG and FIML cannot be directly compared as they are subject to different scaling.

${ }^{46}$ The $R_{O L S}^{2}$ signals sufficient identification with values superior or close to $10 \%$. The negative correlation in Rho in Tables A2 and A4 signals the downward bias in the endogenous variable, which can be seen by comparing Models E and F, and L and M, respectively. Similarly, the positive correlation in Rho in Table A3 signals an upward bias in the endogenous variable (see Models I and $\mathrm{J}$ ).

${ }^{47} \mathrm{~A}$ "hat" above a variable indicates that this variable has been instrumented.

${ }^{48}$ The level of democracy $\left(\Delta\right.$ democracy $\left._{i t}\right)$ and the total debt service $\left(\Delta\right.$ debt $\left._{i t-2}\right)$ loose their significance in Model $\mathrm{J}$ and the population density $\left(\Delta\right.$ density $\left._{i t}\right)$ becomes significant at the $5 \%$ level.

${ }^{49}$ The checks and balances variable $\left(\Delta c h e c k s_{i t}\right)$ looses significance in Model $\mathrm{M}$ and the mainline penetration $\left(\Delta m l_{i t-2}\right)$ and population density $\left(\Delta\right.$ density $\left._{i t}\right)$ variables become significant at respectively the $10 \%$ and $5 \%$ levels.

${ }^{50}$ Recall that increasing values of the variable corruption indicate lower corruption in the government and that, given the way the variable institutional is constructed see section 3 ), lower corruption reflects a better institutional environment.
} 
However, in Tables A2 and A3 explaining the decisions to introduce competition in the digital cellular and the fixed-line segments respectively, the institutional index, the corruption variable $\left(\Delta\right.$ corruption $\left._{i t}\right)$, and the democracy variable $\left(\Delta\right.$ democracy $\left._{i t}\right)$ all have a negative and significant impact (Models F, G, and J).

What about the role of the cost of public funds in the decision to introduce competition? Hypothesis 2 says that a higher cost of public funds should discourage the introduction of competition. Our empirical analysis although supportive of this hypothesis are somewhat mitigated. The results concerning the decision to introduce competition in the analogue cellular and fixed segments support this hypothesis. Indeed, from Table A1 we see that aid per capita $\left(\Delta a i d_{i t-2}\right.$ in Models $\mathrm{A}$ and $\left.\mathrm{B}\right)$ and net taxes on products $\left(\Delta \operatorname{tax}_{i t-3}\right.$ in Model C) have a positive and significant impact on competition. ${ }^{51}$ Moreover, from Table A3 we see that net taxes on products $\left(\Delta \operatorname{tax}_{i t-2}\right.$ in Model J) has also a positive and significant impact on the decision to introduce competition in the fixed-line local segment. In contrast, the results concerning the decision to introduce competition in the digital cellular segment contradict Hypothesis 2. We indeed see from Table A2 that the total debt service $\left(\Delta\right.$ debt $_{i t-2}$ in Model $\mathrm{F}$ ) has a positive and significant impact on this decision and aid per capita $\left(\Delta a i d_{i t-3}\right.$ in Model G) has a negative and significant impact.

Let us now examine the empirical evidence on the role of government commitment, the discount factor, and the returns on investment in the decision to create a separate regulator. Hypothesis 3 states that countries where government commitment is weak, returns on investment are large, and the discount factor is high are likely to establish a separate regulatory authority. ${ }^{52}$ Our results do not seem to confirm the whole claim of this hypothesis. First, assuming that government commitment is reasonably well captured in the institutional index, we see from Model M in Table A4 that it has rather a positive and significant impact on the decision to create a separate regu-

\footnotetext{
${ }^{51}$ Recall that the trust is that there exists a positive (negative) relationship between the cost of public funds and the total debt service (net taxes and aid per capita). In practice, we use these related variables lagged two and three periods and report the coefficients of these lagged variables that are actually significant.

${ }^{52}$ We should emphasize here that the discussion of Hypothesis 3 in section 4.3 has abstracted away from the debate of independence vs. autonomy of the regulator, although the issue has its own importance.
} 
lator (Model M). Second, assuming that the discount factor is reflected in the variable checks and balances $\left(\Delta\right.$ checks $\left.s_{i t}\right)$, we see from this same table that it is not significant once endogeneity problems have been alleviated in Model M. Finally, assuming that the return on investment is well proxied by the variable deployment of fixed lines $\left(\Delta m l_{i t-2}\right)$, we see from the same model $M$ that it has a positive and significant effect on the decision to create a separate regulator, a result that supports the third part of Hypothesis 3.

\section{Determinants of privatization}

Table A5 in the appendix presents the SYS-GMM (one-step robust) estimation results of the regressions with the variable privatization as the dependent variable and the coefficient shown corresponding to regressors in first-differences. This table also exhibits the first and n-th order autocorrelation coefficients of the residuals in first differences, $m 1$ and $m n$, the value of the $J$ statistic for testing the validity of the instruments, the value of the Dif-Sargan statistic that allows to test the validity of the additional SYSGMM conditions, the value of the starting lag of the instruments, $L$, a Wald statistic for testing the joint significance of the temporal dummies, Temporal dummies, the $\mathrm{F}$ statistic for testing the joint significance of the explanatory variables, Goodness-of-fit, and the number of observations actually used.

From this table, it appears that in all the estimations but that of Model $\mathrm{P}$, second-order autocorrelation of the residuals in first differences $(\mathrm{m} 2)$ is rejected using as instruments the initial lag of two and more periods for the variables in levels and one period for the variable in first differences. This confirms the validity of these instruments. In the case of Model $\mathrm{P}$, we find empirical evidence that the disturbance term in levels follows a $M A(2)$. The valid instruments then are the variables in levels lagged 4 and more periods for the equation in first differences and the variables in differences lagged 3 periods for the equation in levels. Moreover, the $J$ test never rejects the validity of the instruments. We also see that the Dif-Sargan test accepts the additional moment conditions required to use the SYS-GMM.

Time specific effects and endogeneity of regressors deserve some attention here. ${ }^{53}$ The presence of time specific effects is tested and rejected in the

\footnotetext{
${ }^{53}$ That endogeneity is a relevant issue in our context has been already discussed. As to time specific effects, their investigation is justified by the occurrence of some important
} 
regression explaining privatization. Hence, time dummies are not included in this regression. ${ }^{54}$ Endogeneity of regressors is checked using the goodnessof-fit criterion. In the privatization regression, only the best model (with no endogenous regressors, except for $\Delta p_{i t-1}$ ) is reported in Table A5.

What are the implications of our empirical results as to the validity of Hypothesis 4 which says that countries with little or extreme corruption in the government should privatize less? We find that when corruption is proxied by the democracy index, it has a negative impact on the privatization decision in Model $\mathrm{N}$, which is not consistent with the hypothesis. Interestingly enough though, thinking of Hypothesis 4 as saying that corruption has a decreasing marginal impact on privatization, we see that it is confirmed. Indeed, from Table A5, we see that the institutional index which, recall, incorporates the corruption level, has a positive impact on the privatization decision and the square of this index has a negative impact in Models $\mathrm{Q}$ and $\mathrm{R}$.

Regarding the hypotheses on the determinants of privatization, Hypothesis 5 says that high costs of public funds and high risks are associated with low privatization. This hypothesis is partially confirmed by our empirical results. The current increase rate of the risk index $\left(\Delta r i s k_{i t}\right)$ has a significant impact on the privatization decision across all Models in Table A5, which is consistent with the hypothesis. ${ }^{55}$ However, the cost of public funds has a positive impact on the decision of privatizing, which is not consistent with the hypothesis. We find that, in growth rates, the lagged (two and three periods) total debt service $\left(\Delta d e b t_{i t-2}, \Delta d e b t_{i t-3}\right)$ has a positive impact on privatization in Models $\mathrm{N}, \mathrm{O}$, and $\mathrm{P}$, the lagged (two and three periods) aid per capita $\left(\Delta a i d_{i t-2}\right.$ and $\left.\Delta a i d_{i t-3}\right)$ has a negative impact in Models $\mathrm{N}, \mathrm{O}$, and $\mathrm{P}$, and the lagged (two periods) net taxes on products $\left(\Delta \operatorname{tax}_{i t-2}\right)$ has a negative impact in Model Q.

events during the period under study including the 1995 "Tequila" crisis, the 1997 SouthAsian crisis, the 1998-1999 financial breakdown, and the introduction of digital systems.

${ }^{54}$ As can be seen from Table A5, the variable Temporal dummies is not significant in Model $\mathrm{O}$ and the Goodness-of-fit test rejects the presence of time specific effects.

${ }^{55}$ Recall that higher values of the risk index ( $r i s k$ ) correspond to lower risk. 


\subsection{Reforms-network expansion simultaneous relation- ship}

In this section, we discuss the implications of our results as far as the simultaneous relationship between the introduction of telecommunications reforms and the deployment of the fixed-line network is concerned. We first put together the empirical elements that will allow us to construct this relationship.

Starting with the impact of the development of fixed service on the decision to reform, we have included the variable fixed-line deployment to explain the decisions to introduce competition in the fixed line local and digital cellular segments, and to create a separate regulator. The specific effects obtained are as follows. The growth of the lagged (one period) fixed service penetration rate $\left(\Delta m l_{i t-1}\right)$ affects positively the decision to introduce competition in the digital cellular segment (Table A2, Models F and G) and in the fixed local segment (Table A3, Models $\mathrm{H}$ and $\mathrm{J}$ ). As to the decision to create a separate regulator, it is found (Table A4, Model M) to be negatively affected by the growth of lagged (two periods) fixed service penetration rate $\left(\Delta m l_{i t-2}\right)$.

Let us now consider the impact of the reforms on fixed service penetration. Table A6 in the appendix displays the results of the regression to look at. This table has the same structure as Table A5 presented in the previous section and, as a general rule, we have made the choice of regressors on the basis of the results of the causality tests discussed in section $4.2 .^{56} \mathrm{We}$ observe that all the reforms variables have been included as regressors except the one used to represent the introduction of competition in the fixed-line local segment. ${ }^{57}$ We find that competition in the analogue cellular segment $\left(\Delta a c_{i t-1}\right)$ has a negative impact on the fixed-line deployment in Models $\mathrm{S}, \mathrm{T}$, and $\mathrm{U}$ whereas competition in the digital cellular segment $\left(\Delta d c_{i t-1}, \Delta d c_{i t-2}\right)$ has a positive impact in Model $\mathrm{S}$ and even when endogeneity is controlled for in Model $\mathrm{U}\left(\Delta d c_{i t-2}\right)$. As to the other reform variables, we see that while the creation of a separate regulator $\left(\Delta r_{i t-2}\right)$ has a positive impact in Model

\footnotetext{
${ }^{56}$ In this table, we report the best model (with the endogenous regressors) in Model $\mathrm{U}$, and, for the purpose of making comparisons, the second best (with no endogenous regressors) in Model S. In particular, Model S includes as endogenous the regressors when a two-way causal relationship is found, that is, the variables competition in the digital cellular segment and creation of a separate regulator.

57 The lack of causality between the introduction of competition and the deployment of service in the fixed service segment is not surprising as it is well known that this market has experiencing heavy business stealing.
} 
$\mathrm{S}$, once endogeneity is accounted for in Model $\mathrm{U}$, the associated coefficient is no longer significant. Finally, privatization $\left(\Delta p r i v a_{i t-1}, \Delta p r i v a_{i t-2}\right)$ has a positive effect on the fixed service segment in Model $\mathrm{S}$ and this impact remains significant $\left(\Delta p r i v a_{i t-1}\right)$ when endogeneity of some regressors is taken into account in Model U.

The results discussed so far indicate that there exists a simultaneous relationship between the decision to introduce competition in the digital cellular segment and the development of the fixed-line segment. More precisely, higher penetration rates in the fixed segment have been an important determinant of the decision to introduce competition in the digital cellular segment and, in turn, competition in this sector has resulted in higher penetration rates. Table 3 below summarizes the quantitative relationships found between the various reform policies considered in this paper and fixed-line deployment. ${ }^{58}$ In addition to showing the simultaneous relationship between digital cellular competition and fixed service deployment, this table includes the results on the other relationships considered that are worth discussing.

If we examine the role played by fixed-line deployment in the reform decision-making process, we find evidence that the lower the fixed-line penetration rate, the more likely a separate regulator will be created and the less competition is introduced in the digital cellular and fixed local segments. A possible explanation of these results is that poorly performing fixed service sectors have called for the creation of a separate regulator to bring remedies while well performing fixed sectors have resulted in the introduction of competition in the digital cellular and fixed segments since those entail high license fees. Let us now turn to an examination of the impact of the reforms on the deployment of fixed infrastructure.

Consider first the results concerning the role of competition. As discussed in the beginning of this section, we have found a positive impact of the introduction of competition in the digital cellular segment on fixed network expansion. In contrast, we have found that the introduction of competition in the analogue cellular segment has a negative impact. ${ }^{59}$ These results demand two remarks. First, the mere fact that we found opposite effects of the

\footnotetext{
${ }^{58}$ Table 3 is basically Table 2 where the causal relationships found are given the quantitative form resulting from the regression analysis.

${ }^{59}$ As mentioned earlier, competition in the fixed local segment has not been found to have a significant impact on network expansion.
} 
two cellular technologies on network expansion justifies ex post our choice of treating them separately. Indeed, the usual practice is to unify these two segments by using an aggregate index of competition in the cellular sector and the empirical findings have been almost systematically a positive impact on the fixed sector. ${ }^{60}$ Second, these results suggest that, when it comes to network expansion, digital cellular service and fixed service are complements while analogue cellular service and fixed service are substitutes. Thinking of competition as fostering service usage, this implication is consistent with the fact that analogue licenses have been introduced before digital licenses and have been mostly granted to the incumbent, in which case no strong competition between fixed service and analogue cellular service can be expected. Moreover, capacity constraints associated with the analogue technology have typically limited the number of issued licenses in the analogue cellular segment.

What about the two other important reform policies, namely, privatization and the creation of a separate regulator? Our work sheds some light on the issue of the impact of privatization which is not settled in the literature. We find evidence in our data set that privatization has a strong positive impact on the fixed service penetration rate. As to the creation of a separate regulator, the data does not seem to show that it has a significant impact on fixed-line deployment.

Table 3

Summary of results: Relationship between reforms and fixed-line deployment

\begin{tabular}{lcccccc}
\hline \hline & $a c$ & $d c$ & $l c$ & $r$ & $p$ \\
\hline reform $\rightarrow$ fixed-line deployment & - & + & NA & NS & + \\
fixed-line deployment $\rightarrow$ reform & NA & + & + & - & NA \\
\hline $\begin{array}{l}\text { Note: NA and NS stand for not applicable and not significant, res- } \\
\text { pectively. }\end{array}$
\end{tabular}

\subsection{Institutional and economic environment determi- nants of reform policies: Summary}

To conclude the discussion of the empirical analysis, we summarize in Table 4 the results on the determinants of the telecommunications reform policies.

\footnotetext{
${ }^{60}$ See section 2.
} 
We can see from this table that the initial performance of the sector, the institutional environment, and the cost of public funds play an important role in the decisions to reform the industry. Let us say a few words about each of the three main reforms, namely, competition, privatization, and creation of a separate regulator, in turn.

Table 4

Summary of results: Determinants of reforms

\begin{tabular}{|c|c|c|c|c|c|}
\hline & $a c$ & $d c$ & $l c$ & $r$ & $p$ \\
\hline $\begin{array}{l}\text { RISK INDEX } \\
\text { risk }\end{array}$ & NA & NA & NA & NA & + \\
\hline $\begin{array}{l}\text { COST OF PUBLIC FUNDS } \\
\text { total debt service } \\
\text { net taxes on products } \\
\text { aid per capita } \\
\text { aggregated }\end{array}$ & $\begin{array}{l}\mathrm{NS} \\
+ \\
+ \\
-\end{array}$ & $\begin{array}{l}+ \\
\text { NS } \\
- \\
+\end{array}$ & $\begin{array}{l}\text { NS } \\
+ \\
\text { NS } \\
-\end{array}$ & $\begin{array}{l}\text { NA } \\
\text { NA } \\
\text { NA } \\
\text { NA }\end{array}$ & $\begin{array}{l}+ \\
- \\
- \\
+\end{array}$ \\
\hline $\begin{array}{l}\text { INSTITUTIONAL ENVIRONMENT INDICES } \\
\text { corruption } \\
\text { institutional index } \\
\text { democracy index } \\
\text { institutional index (square) } \\
\text { democracy index (square) }\end{array}$ & $\begin{array}{l}\text { NS } \\
+ \\
\text { NS } \\
\text { NA } \\
\text { NA }\end{array}$ & $\begin{array}{l}\text { NS } \\
- \\
- \\
\text { NA } \\
\text { NA }\end{array}$ & $\begin{array}{l}- \\
\text { NS } \\
\text { NS } \\
\text { NA } \\
\text { NA }\end{array}$ & $\begin{array}{l}\text { NS } \\
+ \\
\text { NS } \\
\text { NA } \\
\text { NA }\end{array}$ & $\begin{array}{l}\mathrm{NS} \\
- \\
+ \\
+ \\
+ \\
\mathrm{NS}\end{array}$ \\
\hline $\begin{array}{l}\text { DISCOUNT FACTOR } \\
\text { checks and balances }\end{array}$ & NA & NA & NA & NS & NA \\
\hline $\begin{array}{l}\text { RETURNS ON INVESTMENT } \\
\text { fixed-line deployment }\end{array}$ & NA & + & + & - & NA \\
\hline
\end{tabular}

We have already mentioned the positive impact of fixed service penetration rates on the decision to introduce competition in both the digital cellular and fixed local markets. But, besides fixed service penetration rates what else has a significant impact on the introduction of competition in the telecommunications industry? We find that that the weaker the institutional environment, the less likely to find competition in the analogue cellular market and the more likely to find competition in the digital cellular and fixed local markets. The decision to introduce competition is also found to be markedly influenced by a country's financial situation. Our analysis has shown that the higher the cost of public funds, the more likely to find competition in the digital cellular market and the less likely to find competition in the analogue cellular and fixed service markets.

As to the privatization of the fixed service incumbent, we find that the likelihood that it takes place is positively affected by a deterioration of the 
institutional environment and a higher cost of public funds, and negatively by a higher country risk. A justification of these results is that in a country with high risk, the government anticipates that the incumbent will be sold at a discounted price and thus refrains from privatizing. Finally, concerning the decision to create a separate regulatory authority, we find that a well performing fixed service sector (higher penetration rates) affects this decision negatively whereas a better institutional environment affects it positively.

\section{Conclusion}

This paper has demonstrated the importance of the institutional and macroeconomic features of developing countries for understanding the evolution of their telecommunications industry over the past two decades. To show this point, we have set an empirical strategy to identify the key determinants of the three main policy initiatives that have been at the heart of the reforms of the telecommunications industry, namely, competition, privatization, and the (re)structuring of regulation. To give more robustness to our argument, from both a technical (investigating causality endogeneity) and a policy (accounting for the rational of the reforms) viewpoint, we have also investigated the extent to which these policies have translated into actual deployment of telecommunications infrastructure.

Our econometric analysis of a 1985-1999 database on 86 developing countries in the form of a time-series-cross-section database indeed suggests that sectoral but also institutional and financial factors are important determinants of the actual reforms implemented in these countries. For technological, historical, and jurisdictional reasons concerning the analogue and digital segments of the cellular market, we departed from the standard approach by treating separately these two segments. The separate treatment of these two segments allowed us to obtain more disaggregated results than those obtained in the literature as most of the studies have typically merged them.

Many factors warrant such a separate treatment. Capacity constraints associated with the analogue technology are among the major reasons why digital technology is relatively more appealing for the rapidly increasing cellular market. Indeed, digital technology allows to allocate more users within the same coverage area and more information can be simultaneously sent 
and received by each phone user. Moreover, while analogue technology does not allow for wireless data services, digital technology includes voice mail, caller identification, call waiting, access to internet, and short message system (SMS). In addition, digital technology is less prone than analogue technology to interference and has better attributes related to privacy and security. A drawback of the digital technology, however, is that, unlike the analogue technology, there is currently no unified system and roaming between systems can be expensive.

We have uncovered a positive relationship between the decision to introduce competition in the digital cellular segment and the growth of the fixed-line segment, whereas a negative relationship has been found between the decision to introduce competition in the analogue cellular segment and the growth of the fixed-line segment. These results reveal that the positive effect of competition in the cellular market on the fixed service market reported in the literature might in fact mainly reflect the impact of competition in the digital cellular segment. Analogue cellular appears therefore as a substitute to the fixed service whereas digital cellular appears as a complement. The analysis has indeed shown that the digital cellular and fixed markets have benefited from each other.

As to the institutional and country risk effects, we find that countries facing increasing institutional risk and financial constraints are more likely to introduce competition in the digital cellular segment and to privatize the fixed-line incumbent. In turn, these policies are those that were found to enhance the deployment of fixed-line infrastructure. ${ }^{61}$ In contrast, competition in the analogue cellular segment and the creation of a separate regulator are found to be less likely to be introduced in countries facing increasing institutional risk and budget constraints. Their impact on fixed network deployment is found to be negative or non significant.

How should one interpret our results that highlight the importance of the quality of the institutional environment and the state of the government's

\footnotetext{
${ }^{61}$ We should note that our result on the positive impact of privatization on fixed-line deployment is in contrast with the null or negative impact found in the literature. This might be due to the fact that most empirical studies have aggregated data on countries with different levels of development. Separating data according to GDP, Gasmi et al (2006) find a positive impact in data on developing countries and a negative impact in data on developed countries.
} 
finances in the determination of the implemented reforms? Developing countries with higher institutional risk and tighter financial constraints are more likely to promote policies, such as allowing entry into the digital cellular segment and privatizing the fixed-line incumbent, that attract a larger number of investors whose rents can be extracted through the license fees, red tape, or else. ${ }^{62}$ By the same token, these countries are less supportive of those reforms that are likely to provide them with less cash, such as cellular competition in the analogue segment and the creation of a regulator. Except in extreme cases of high corruption, the economically profitable reforms promoted by the governments are those that are likely to be successful, in particular, those that are expected to have a significant positive impact on the telecommunications infrastructure. ${ }^{63}$ This argument may partly explain the impressive growth of telecommunications in Sub-Saharan Africa in recent years.

\footnotetext{
${ }^{62}$ One can take the view that governments promote these reforms in order to circumvent institutional and economic country weaknesses. Nevertheless, this would imply that governments can anticipate which policies will deliver better outcomes in terms of service deployment.

${ }^{63}$ In this paper, we have discussed the positive impact of competition in the digital cellular segment and privatization on fixed-line deployment, but we did find evidence of a (standard) positive impact on cellular subscription as well and the results are available from the authors upon request.
} 


\section{Appendix}

Table A1

Cellular (analogue) competition parameter estimates

\begin{tabular}{|c|c|c|c|}
\hline$a c_{i t}$ & $\begin{array}{l}\text { Model A } \\
\text { CLOGLOG }\end{array}$ & $\begin{array}{c}\text { Model B } \\
\text { CLOGLOG } \\
\text { W/DUMMIES }\end{array}$ & $\begin{array}{l}\text { Model C } \\
\text { CLOGLOG }\end{array}$ \\
\hline $\begin{array}{l}\Delta_{\Delta} \text { institutional }_{i t} \\
\Delta \text { democracy }_{i t} \\
\Delta \text { debt }_{i t-2} \\
\Delta \text { tax }_{i t-2} \\
\Delta \text { aid }_{i t-2} \\
\Delta \text { debt }_{i t-3} \\
\text { taax }_{i t-3} \\
\Delta \text { aid }_{i t-3} \\
\Delta \text { rural }_{i t} \\
\Delta \text { density }_{i t} \\
\text { counter_ana }_{i t}\end{array}$ & $\begin{array}{l}0.168^{* * *} \\
0.182 \\
-0.011 \\
0.063 \\
0.009^{* * *}\end{array}$ & $\begin{array}{c}0.126^{* *} \\
0.122 \\
-0.010 \\
0.047 \\
0.010^{* * *}\end{array}$ & $\begin{array}{l}0.003 \\
0.113^{* *} \\
0.001 \\
0.324 \\
-0.021 \\
-0.520^{* *}\end{array}$ \\
\hline $\begin{array}{l}\text { Log-likelihood } \\
\text { Temporal dummies LR } \\
\text { Obs }\end{array}$ & $\begin{array}{c}-176.86 \\
643 \\
\end{array}$ & $\begin{array}{c}-169.64 \\
16.43 \\
643 \\
\end{array}$ & $\begin{array}{c}-167.85 \\
586 \\
\end{array}$ \\
\hline
\end{tabular}

Table A2

Cellular (digital) competition parameter estimates

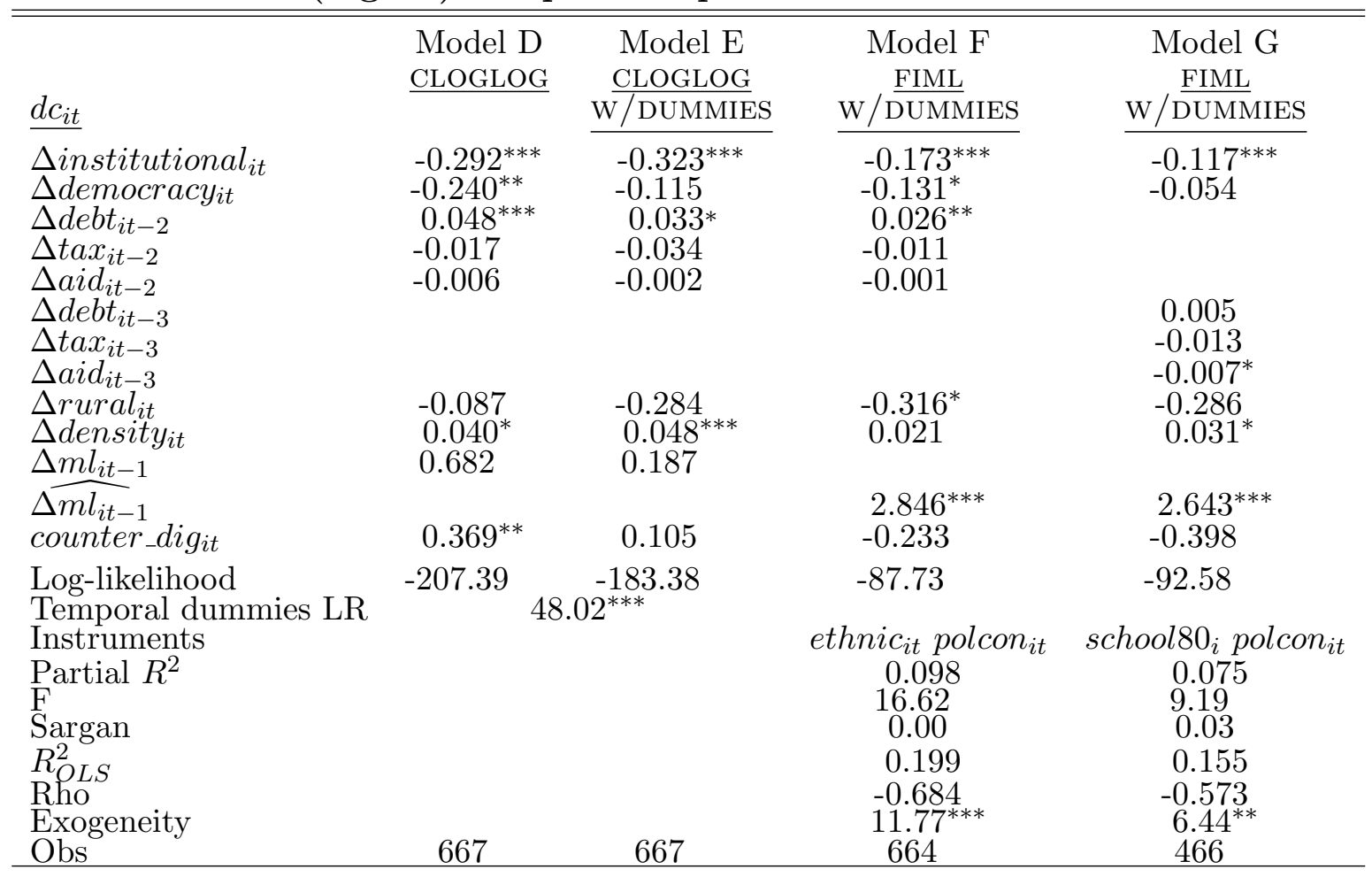


Table A3

Fixed-line (local) competition parameter estimates

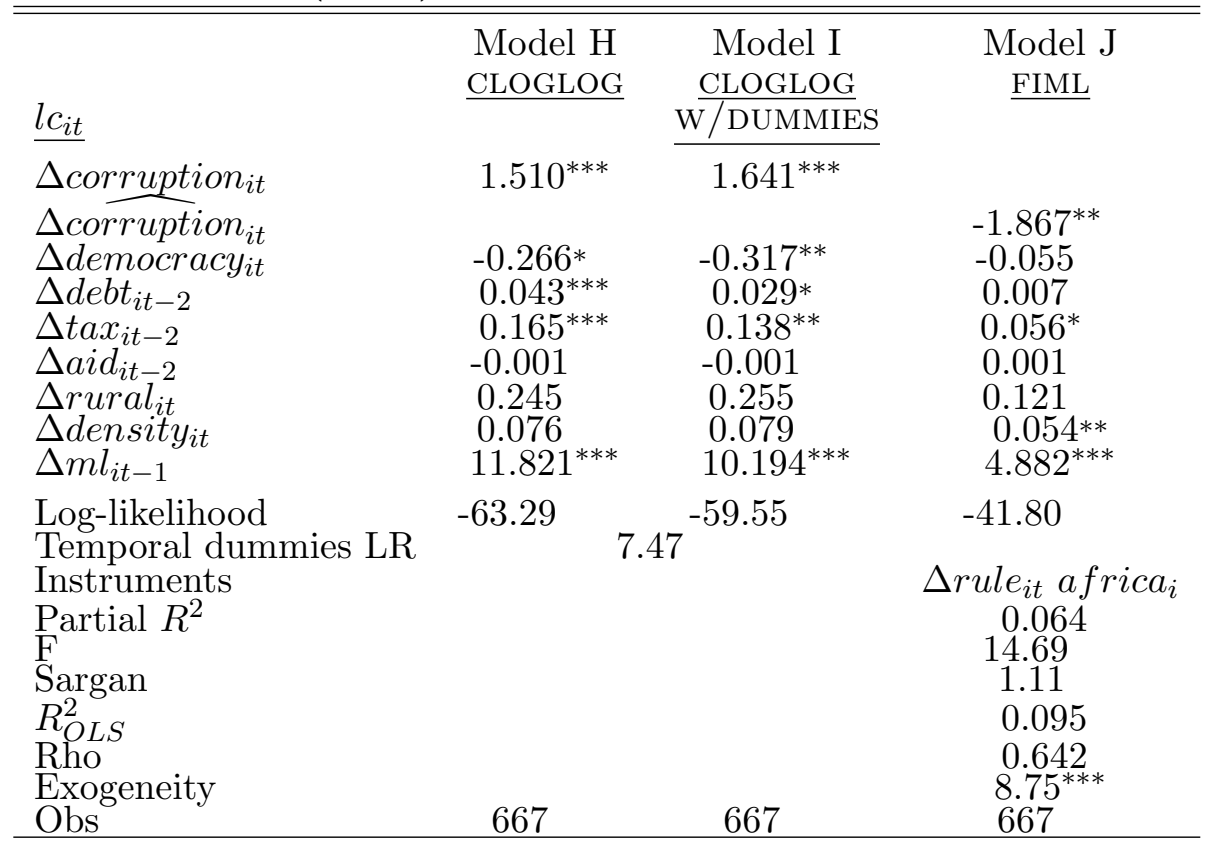

Table A4

Separate regulator parameter estimates

\begin{tabular}{|c|c|c|c|}
\hline$\underline{r_{i t}}$ & $\begin{array}{l}\text { Model K } \\
\text { CLOGLOG } \\
\end{array}$ & $\begin{array}{c}\text { Model L } \\
\text { CLOGLOG } \\
\text { W/DUMMIES }\end{array}$ & $\begin{array}{c}\text { Model M } \\
\text { FIML } \\
\text { W/DUMMIES }\end{array}$ \\
\hline $\begin{array}{l}\Delta \text { institutional }_{i t} \\
\text { institutional }_{i t} \\
\Delta \text { democracy }_{i t} \\
\Delta \text { checks }_{i t} \\
\Delta \text { import }_{i t} \\
\Delta \text { staff }_{i t} \\
\Delta \text { rural }_{i t} \\
\Delta \text { density }_{i t} \\
\Delta \text { ml }_{i t-2}\end{array}$ & $\begin{array}{l}-0.106 \\
\\
-0.256 \\
0.221^{*} \\
0.059^{* * *} \\
-1.890^{*} \\
0.202 \\
-0.047 \\
-1.835\end{array}$ & $\begin{array}{l}-0.131 \\
-0.227 \\
0.181^{*} \\
0.072^{* * *} \\
-3.047^{*} \\
0.365 \\
-0.077 \\
-3.615\end{array}$ & $\begin{array}{l}0.296^{* *} \\
-0.061 \\
0.048 \\
0.038^{* * *} \\
0.762 \\
0.083 \\
-0.063^{* *} \\
-2.197^{*}\end{array}$ \\
\hline $\begin{array}{l}\text { Log-likelihood } \\
\text { Temporal dummies LR } \\
\text { Instruments } \\
\text { Partial } R^{2} \\
\text { F } \\
\text { Sargan } \\
R_{O L S}^{2} \\
\text { Rho } \\
\text { Exogeneity } \\
\text { Obs }\end{array}$ & $\begin{array}{r}-130.68 \\
47\end{array}$ & $4^{-106.31}$ & $\begin{array}{c}-1485.61 \\
\text { protest } 80_{i} \text { africa } \\
0.032 \\
12.50 \\
1.32 \\
0.126 \\
-0.657 \\
4.24^{* *} 688\end{array}$ \\
\hline
\end{tabular}


Table A5

Privatization parameter estimates

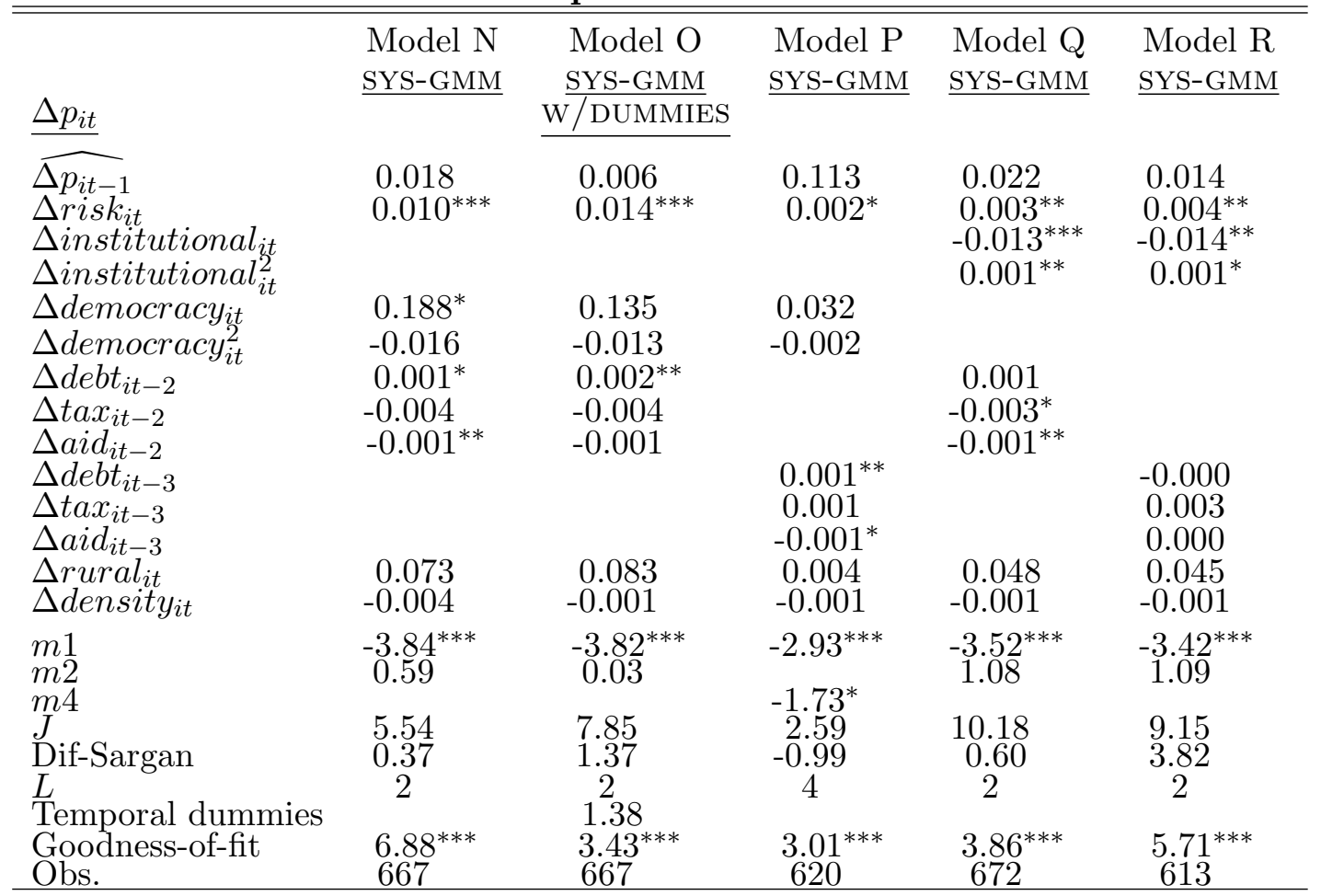

Note: The starting lag for the instruments is $L$ and $(L-1)$ for the equation in first differences and levels, respectively. 
Table A6

Fixed-line deployment parameter estimates

\begin{tabular}{|c|c|c|c|}
\hline$\Delta \log \left(m l_{i t}\right)$ & $\begin{array}{c}\text { Model S } \\
\text { SYS-GMM } \\
\end{array}$ & 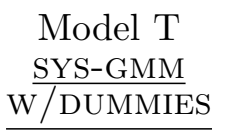 & $\begin{array}{l}\text { Model U } \\
\text { SYS-GMM } \\
\end{array}$ \\
\hline $\begin{array}{l}\left.\Delta \widehat{\log (m l}_{i t-1}\right) \\
\Delta p_{i t-1} \\
\Delta p_{i t-2} \\
\Delta a c_{i t-1} \\
\Delta d c_{i t-1} \\
\Delta d c_{i t-2}\end{array}$ & $\begin{array}{l}0.558^{* * *} \\
0.107^{* *} \\
0.067^{* *} \\
-0.016^{* * *} \\
0.031^{* *} \\
0.011^{* *}\end{array}$ & $\begin{array}{l}0.491^{* * *} \\
0.104^{*} \\
0.066^{*} \\
-0.014^{* *} \\
0.025 \\
0.007\end{array}$ & $\begin{array}{l}0.529^{* * *} \\
0.099^{*} \\
0.068^{\text {* }} \\
-0.017^{* * *}\end{array}$ \\
\hline $\begin{array}{l}\widehat{\Delta d c_{i t-1}} \\
\widehat{\Delta d c_{i t-2}} \\
\Delta r_{i t-2}\end{array}$ & $0.023^{*}$ & $0.024^{*}$ & $\begin{array}{l}0.001 \\
0.019^{*}\end{array}$ \\
\hline $\begin{array}{l}\widehat{\Delta r_{i t-2}} \\
\Delta \text { institutional }_{i t} \\
\Delta \text { democracy }_{i t} \\
\Delta \text { rural }_{i t} \\
\Delta \text { density }_{i t}\end{array}$ & $\begin{array}{l}0.002^{* *} \\
0.007 \\
-0.006 \\
-0.006\end{array}$ & $\begin{array}{c}0.003^{*} \\
0.010 \\
-0.012 \\
-0.006\end{array}$ & $\begin{array}{l}0.042 \\
0.002^{* *} \\
0.004 \\
-0.001 \\
-0.002\end{array}$ \\
\hline $\begin{array}{l}m 1 \\
m 2 \\
J \\
\text { Dif-Sargan } \\
L \\
\text { Temporal dummies } \\
\text { Goodness-of-fit } \\
\text { Obs. }\end{array}$ & $\begin{array}{l}-4.93^{* * *} \\
0.40 \\
55.04 \\
-3.33 \\
\quad 2 \\
17.71^{* * *} \\
775\end{array}$ & $\begin{array}{l}-4.88^{* * *} \\
0.50 \\
46.88 \\
-2.63 \\
2 \\
1.48 \\
17.43^{* * *} \\
775 \\
\end{array}$ & $\begin{array}{l}-4.99^{* * *} \\
0.76 \\
57.88 \\
-3.01 \\
2 \\
20.41^{* * *} \\
775 \\
\end{array}$ \\
\hline
\end{tabular}

Note: The starting lag for the instruments is $L$ and $(L-1)$ for the equation in first differences and levels, respectively. 


\section{References}

Arellano, M. and S. Bond, 1995, "Some tests of specification for panel data: Monte Carlo evidence and an application to employment equations," Review of Economic Studies, 58: 277298.

and O. Bover, 1995, "Another look at the instrumental variable estimation of error-component models," Journal of Econometrics, 68: 29-51.

Auriol, E. and P. Picard, 2004, "Privatizations in developing countries and the government's budget constraint," Nota di Lavoro 75.2002, Fondazione Eni Enrico Mattei, Corso Magenta 63 - I - 20123 Milano Italy.

Banerjee, A. and A. J. Ros, 2000, "Telecommunications privatization and tariff rebalancing: Evidence from Latin America," Telecommunications Policy, 24: 233-52.

Beck, N., Katz, J. and R. Tucker, 1998, "Taking time seriously in binary: Time-series-cross-section analysis with a binary dependent variable," American Journal of Political Science, 42: 1260-88.

and J. Katz, 2004, "Time-series-cross-section issues: Dynamics," Paper presented at the 2004 Annual Meeting of the Society for Political Methodology, Stanford University.

Bliss, C. and R. Di Tella, 1997, "Does competition kill corruption?," Journal of Political Economy, 105: 1001-23.

Blundell, R. and S. Bond, 1998, "Initial conditions and moment restrictions in dynamic panel data models," Journal of Econometrics, 87: 115-143.

Bortolotti, B. and D. Siniscalco, 2004, The challenges of privatization - An international analysis, Oxford University Press.

Emerson, P., 2006, "Corruption, competition and democracy," Journal of Development Economics, 81: 193-212. 
Evans, J., Levine, P. and F. Trillas, 2005, "Lobbies, delegation and the under-investment problem in regulation," Working paper Universidad Autónoma de Barcelona.

Fink, C., Mattoo, A. and R. Rathindran, 2002, "An assessment of telecommunications reform in developing countries," The World Bank Policy Research Working Paper 2909.

Gasmi, F., Noumba, P., and L. Recuero Virto, 2006, "Political accountability and regulatory performance in infrastructure industries: An empirical analysis," The World Bank Economic Review, forthcoming.

Ghosh Banerjee, S. and D.A. Rondinelli, 2003, "Does foreign aid promote privatization? Empirical evidence from developing countries," World Development, 31: 1527-48.

Gual, J. and F. Trillas, 2006, "Telecommunications policies: Measurement and determinants," Review of Network Economics, 5: $249-72$.

Gutierrez, L. H., 2003, "The effect of the endogenous regulation on telecommunications expansion and efficiency in Latin America," Journal of Regulatory Economics, 23: 257-86.

Holtz-Eakin, D., Newey, W. and H.S. Rosen, 1988, "Estimating vector autoregressions with panel data," Econometrica, 56: 1371-95.

Laffont, J.J., 2005, Regulation and development, Cambridge University Press.

and T. N'Guessan, 1999, "Competition and corruption in an agency relationship," Journal of Development Economics, 60: 271-95.

Li, W., Qiang, C. and L.C. Xu, 2005, "Regulatory reforms in the telecommunications sector in developing countries: The role of democracy and private interests," World Development, 33: 1307-24. 
and L.C. Xu, 2002, "The political economy of privatization and competition: Cross-country evidence from the telecommunications sector," Journal of Comparative Economics, 30: 439-62.

, 2004, "The impact of privatization and competition in the telecommunications sector around the world," The Journal of Law and Economics, 47: 395-430.

Martimort, D. and S. Straub, 2006, "Privatization and corruption," Mimeo, Toulouse School of Economics.

McNary, R., 2001, "The network penetration effects of telecommunications privatization and competition," Mimeo, Stanford University.

Rivers, D., and H. Vuong, 1988, "Limited information estimators and exogeneity tests for simultaneous probit models," Journal of Econometrics, 39: 347-66.

Ros, A.J., 1999, "Does ownership and competition matter? The effects of telecommunications reform on network expansion and efficiency," Journal of Regulatory Economics, 15: 65-92.

- , 2003, "The impact of the regulatory process and price cap regulation in Latin American telecommunications markets," Review of Network Economics, 2: 270-86.

Wallsten, S. J., 2000, "Telecommunications privatization in developing countries: The real effects of exclusivity periods," Stanford Institute for Economic Policy Research Paper 99-21. , 2001, "An econometric analysis of competition, privatization, and regulation in Africa and Latin America," The Journal of Industrial Economics, 49: 1-19.

Warlters, M., 2004, "Infrastructure privatization and the marginal cost of public funds," $\mathrm{PhD}$ Dissertation, Université de Toulouse I. 